\title{
Abdominal Pregnancy With a Full Term Live FETUS: CASE REPORT
}

\author{
A. Y. Isah, Y. Ahmed, E. I. Nwobodo and B. A. Ekele \\ Department of Obstetrics and Gynaecology, Usmanu Danfodiyo University Teaching Hospital, Sokoto, Nigeria \\ Reprint request to: $\mathrm{Dr}$ AY Isah, Department of Obstetrics and Gynaecology, Usmanu Danfodiyo University \\ Teaching Hospital, P.M.B 2370. Sokoto, Nigeria. E-mail: isahay@yahoo.com
}

\begin{abstract}
This is a case report of an abdominal pregnancy that was carried to term with live fetus. Illiteracy, poverty and lack of antenatal care had resulted in her late presentation. Bleeding per vagina, persistence abdominal pain, weight loss and pallor were the main clinical features. She had laparotomy and delivery of a live fetus.
\end{abstract}

Key words: abdominal pregnancy, term, live fetus

\begin{abstract}
Résumé
Ce cas clinique se rapporte à une grosses abdominale qui s'est déroulée jusqu'à terme avec un fétus vivant. L'ignorance, la pauvreté et l'absence de consultation prénatale ont abouti à une consultation tardive. Un saignement par voie vaginale, une douleur abdominale persistante, une perte de poids et une pâleur étaient les éléments caractéristiques au plan clinique. Elle a bénéficié d'une laparotomie avec accouchement d'un fœtus vivant.
\end{abstract}

Mots clés: Grossesse abdominale, terme, fetus vivant

\section{Introduction}

Abdominal pregnancy is a very rare type of ectopic gestation, with its frequency been directly related to the frequency of ectopic gestation in the population 1,2 . About $2 \%$ of all pregnancies are ectopic and abdominal pregnancy where implantation occurs within the peritoneal cavity is much more uncommon, accounting for $1 \%-4 \%{ }^{2}$ of all ectopic pregnancies. It is more common in developing countries $^{1}$ and is life threatening condition that requires early and accurate diagnosis if the severe complications associated with it are to be avoided. ${ }^{2}$

The clinical presentation of abdominal pregnancy is variable and physical examination by its self may be insufficient for the diagnosis. ${ }^{2,3}$ Clinical features such as persistent abdominal pain, painful fetal movements, weight loss, abnormal presentations, uneffaced and displaced cervix, vagina bleeding and, palpation of an abdominal mass distinct from the uterus should raise the suspicion. ${ }^{1,4}$ To assist in preoperative diagnosis and reduce errors, an array of diagnostic procedures including oxytocin stimulation, abdominal $x$-ray, hysterosalpingography and ultrasound scan have been used. ${ }^{5,6}$ Recently, an ultrasound diagnosis aided by the balloon of a Foley's catheter in the uterine cavity was reported in Nigeria. ${ }^{2}$ Most cases of advanced abdominal pregnancy are associated with dead fetuses. ${ }^{2,4,5} \mathrm{~A}$ case of advance abdominal pregnancy with live fetus following 15-year of primary infertility is hereby presented.

\section{Case report}

A 30-year-old unbooked primigravida presented with complaints of amenorrhoea of 10-month duration, abdominal discomfort of 9 months and sodden onset of vaginal bleeding of one day duration. Quickening occurred at 5-month of pregnancy and fetal movements were associated with abdominal pain. 
Examination revealed evidence of wasting with mild pallor. Cardiovascular and respiratory systems were normal. The abdomen was distended abdomen with easily observed fetal movements and was moderately tender. Pelvic examination revealed blood stained vulva and uneffaced cervix with OS closed. The uterus was slightly bulky and appeared separate from the fetus. The ultrasound report revealed a slightly bulky uterus with a live extra uterine singleton fetus at 39 weeks of gestation. Her packed cell volume was $28 \%$ and anemia was corrected using a pint of compatible blood.

At laparotomy, the findings were; a live male fetus floating within the abdominal cavity, placenta attached to the antero - fundal aspect of the uterus and, slightly enlarged uterus with grossly normal tubes and ovaries. The placenta was stripped off with little difficulty and hemostasis at the placenta bed was secured. The estimated blood loss was $900 \mathrm{mls}$ and two units of blood were transfused intra operatively. The fetus weighed $3.20 \mathrm{~kg}$ with Apgar scores of 7 and 8 in the 1st and 5 th minutes respectively. He was grossly normal. The patient had uneventful postoperative recovery and was discharge home on the 8th post operative day in satisfactory condition.

\section{Discussion}

Abdominal pregnancy is a rare Obstetric complication with high maternal and even higher perinatal mortality. ${ }^{5}$ Its diagnosis is difficult and a high index of suspicion is important in recognizing the condition. ${ }^{2,5,6}$ Persistence abdominal pain as in this report, is the commonest symptom. ${ }^{1,4,5}$ Other clinical features include painful fetal movements, weight loss, vaginal bleeding and uneffaced cervix. These features supported by Ultrasonography made the diagnosis relatively easy in this patient.

Management of abdominal pregnancy poses a clinical challenge because of risk of maternal death from hemorrhage and the possibility of congenital abnormalities. ${ }^{5}$ The widely accepted treatment is immediate laparotomy because of the above complications. ${ }^{6}$ However, there has been debate regarding the use of a more conservative approach if the pregnancy is discovered after 24 weeks of gestation and the fetus is alive. ${ }^{1}$ This approach should only be undertaken if the patient can be kept under strict observation, preferably in Hospital. ${ }^{1,3}$ One of the challenging problems during laparotomy for abdominal pregnancy is risk of massive hemorrhage when attempts are made to remove the placenta. ${ }^{5}$ It is advised that except the entire blood supply to the placenta can be secured with minimal risk to the patient; the placenta is best left in situ. ${ }^{3}$ use of methotraxate to hasten placental involution and resorption has been reported. ${ }^{5}$ Owing to the site of implantation, removal of the placenta in this case was relatively easy. Since most cases of advanced abdominal pregnancy are associated with fetal demise, ${ }^{2,4,5}$ delivery of live fetus at term in this case is interesting. At postnatal clinic, the patient's general condition was satisfactory. The baby had weighed $3.8 \mathrm{~kg}$ and had remained grossly normal. The need for antenatal care in subsequent pregnancies and hospital delivery was emphasized to the couple at discharge from the postnatal clinic.

\section{References}

1. Ifenne DI, Shittu SO, Mandara MU. Advanced abdominal pregnancy with a live fetus. Trop J Obstet Gynaecol. 1999;16:63-65.

2. Ekele BA, Ahmed Y, Nnadi D, Ishaku K. Abdominal pregnancy: ultrasound diagnosis aided by the balloon of a Foley catheter. Acta Obstet Gynecol Scand. 2005;84:701-2.

3. Mutazedian S. Term asymptomatic abdominal pregnancy with good maternal and perinatal outcome; a case report. Ir J Med Sci. 2000;25:7680.

4. Nwobodo El. Abdominal pregnancy: a case report. Ann Afr Med. 2004;3:195-196.

5. Gradzinskas JG. Abdominal pregnancy In: Edmond OK (ed). Dewhurst's text book of Obstetrics and Gynaecology for Postgraduates. Blackwell, Edinburgh, 1999;70.

6. Martin JN, Sessams JK, Martin RW. Abdominal pregnancy: current concept of management. Obstet Gynecol. 1998;71:549-557. 